\title{
The effect on nitrogen oxide emission from agricultural soils
}

\author{
Yulia Kolesnikova ${ }^{1}$, Viktoriia Semal ${ }^{1,2 *}$ Olga Nesterova $^{1}$, Simona Castaldi ${ }^{3}$, \\ Mariya Bovsun ${ }^{1}$, Anastasia Brikmans ${ }^{1}$, Anastasia Popova ${ }^{1,2}$, and Elena Suvorova ${ }^{1}$ \\ ${ }^{1}$ Far Eastern Federal University, Sukhanova Str. 8, 690090, Vladivostok, Russia \\ ${ }^{2}$ Federal Scientific Center of the East Asia Terrestrial Biodiversity, Prospekt Stoletiya Vladivostoka \\ 159, 690022, Vladivostok, Russia \\ ${ }^{3}$ University of Campania Luigi Vanvitelli, Abramo Lincoln St.5, 81100, Caserta, Italy
}

\begin{abstract}
The study investigates the effect of biochar on nitrous oxide emission in Endoargic Anthrosols in the southern territory of the Russian Far East. Biochar (bio-charcoal) was applied in the amounts of $1 \mathrm{~kg} / \mathrm{m}^{2}$ and $3 \mathrm{~kg} / \mathrm{m}^{2}$ in combination with organic and mineral fertilizers to drained and drain-free fields during the vegetation season, and the five-gas analyzer G2508 (Picarro) was used. Cumulative flows of N2O were estimated. The analysis revealed that biochar reduces the emissions and the cumulative flow of nitrous oxide. The higher the dose of biochar, the lower the emission and cumulative flows of nitrous oxide, regardless of a drainage system. Biochar $\left(1 \mathrm{~kg} / \mathrm{m}^{2}\right)$ reduced the cumulative $\mathrm{N} 2 \mathrm{O}$ flow from the soil by $52.2 \%$ throughout the experiment conducted, while a dose of $3 \mathrm{~kg} / \mathrm{m}^{2}$ allowed for $97.8 \%$ reduction. The study found that organic and mineral fertilizers can be effectively used in combination with biochar, as N2O emission from the soil with mineral fertilizers is significantly higher than from the soil with organic fertilizers. Biochar $\left(1 \mathrm{~kg} / \mathrm{m}^{2}\right)$ combined with organic fertilizers reduces $\mathrm{N} 2 \mathrm{O}$ emission by $53.7 \%$, while a dose of 3 $\mathrm{kg} / \mathrm{m}^{2}$ can reduce emissions by $88.9 \%$. Biochar $\left(1 \mathrm{~kg} / \mathrm{m}^{2}\right)$ combined with mineral fertilizers reduced the flow of $\mathrm{N} 2 \mathrm{O}$ by $17.5 \%$, while a $3 \mathrm{~kg} / \mathrm{m}^{2}$ dose of biochar used with mineral fertilizers reduced the emission by $85.3 \%$.
\end{abstract}

\section{Introduction}

The world's population reached 7 billion people by 2012, and according to the results of mathematical modeling, it will exceed 9 billion by 2050 [1]. To ensure food supplies for the whole of humanity, it will be necessary to increase the current yield by about $70 \%$ all over the world and by nearly $100 \%$ in the developing countries [2]. And to meet the growing demand for food, it is vital to enhance soil productivity with the help of agricultural methods [3].

To improve productivity and yields, nitrogen, phosphorus and potash fertilizers are applied to the soil. The use of organic and mineral nitrogen fertilizers around the world has

\footnotetext{
*Corresponding author: semal.va@dvfu.ru
} 
increased almost ninefold over the last fifty years (Ladha et al., 2016). Yet, the larger part of fertilizers is not absorbed by plants but instead, it is washed into groundwater or evaporated into the atmosphere [4]. Thus, about 30\% of the applied nitrogen fertilizers disappear from the soil in the form of nitrous oxide compounds [5]. This aggravates the natural greenhouse effect and can lead to further warming of the Earth's surface and adversely affect natural ecosystems and humankind.

One of the relevant and environmentally friendly solutions to the global warming problem seems to be the use of biochar as a unique soil ameliorant, which, on the one hand, can enhance the effect of fertilizers, and, on the other, help reduce greenhouse gas emissions.

A lot of research on global warming has been published over the last few decades. The academic community is seeking different ways of mitigating greenhouse gas impact. Among these gases, nitrous oxide produces the most detrimental effect on the ozone layer being 310 times more destructive than carbon dioxide [6,7].

A source of nitrogen oxide emissions is mostly agricultural soils. For instance, $79 \%$ of all NOx in 2017 were emissions from agricultural soils [8]. Hence, the development of agricultural technologies that can reduce greenhouse gas emission from the soil seems quite an urgent issue. And, according to some experts, the use of biochar could be a reasonable solution.

Nitrogen oxide originates in the soil mainly as a microbial process where nitrate bacteria (nitrifiers) oxidize $\mathrm{NH}^{4+}$ under aerobic conditions, and denitrifying agents restore $\mathrm{NO}^{3-}$ under anaerobic conditions [9]. The effect of biochar on $\mathrm{N}_{2} \mathrm{O}$ emission from the soil may depend on soil moisture. Thus, under aerobic conditions, at a low moisture level (less than $80 \%$ ), biochar can increase $\mathrm{N}_{2} \mathrm{O}$ emission, as it serves an extra source of nitrogen for the nitrification process. But in the condition of high soil moisture $(>80 \%)$, where the denitrification process prevails over nitrification, biochar reduces $\mathrm{N}_{2} \mathrm{O}$ emissions from soil, thus ensuring full denitrification resulting in $\mathrm{N}_{2}$ release [10].

The intensity of nitrification and denitrification in agricultural soils and nitrogen emissions depend on many factors, such as the soil type, the diversity of soil microbial flora, the moisture, water and air regimes of soils, the ratio of carbon and total nitrogen, and ammoniacal and nitric forms of nitrogen [11, 12].

Some researchers $[10,12]$ suggest that biochar reduces nitrogen oxide emissions by changing the activity of nitrifying and denitrifying microorganisms. Another reason for reducing the emissions can be that biochar immobilizes microbial enzymes.

The reduction of mineral nitrogen $\left(\mathrm{NH}^{4+}-\mathrm{N}\right)$ after treating the soil with biochar is the main reason for the decrease in $\mathrm{N}_{2} \mathrm{O}$ emissions [13]. Nitrogen oxide emissions correlate with soil urease activity, while biochar, by lowering soil acidity (and increasing $\mathrm{pH}$ values), limits urease and reduces NO emissions from the soil [14].

Differences in biochar effect on nitrous oxide emissions are associated with its original raw material and production technology. The biochar made at $350{ }^{\circ} \mathrm{C}$ significantly decreases nitrous oxide emission compared to the biochar made at $550{ }^{\circ} \mathrm{C}$ [15]. Under pyrolysis at temperatures below $350{ }^{\circ} \mathrm{C}$, biochar has a weak and insignificant effect on nitrous oxide emissions from the soil. This can be explained by its weaker aromatic structure and lower surface area, which provide less potential for interaction with $\mathrm{N}_{2} \mathrm{O}$ [16].

Biochar has a high-porous structure that determines the size of its surface area and the rate of interphase interactions, and it also favorably affects microbial activity [17]. Such high porosity of biochar ensures its high sorption properties. Biochar can absorb water whose mass exceeds its weight. Small particles of biochar can absorb water weighing 3 times the weight of biochar [18].

A significant factor in reducing nitrous oxide emissions from soils is the dosage of biochar. After a two-year field experiment X. Lu et al. [19] confirmed a positive effect of 
biochar on the emission of nitrous oxide. In their experiment, they used biochar produced from bamboo leaves at $500{ }^{\circ} \mathrm{C}$. During the first year of the experiment, nitrous oxide emissions decreased by $14.3 \%, 21.0 \%$, and $28.2 \%$, with doses of biochar being 2,5 and 10 tons per hectare, respectively. However, during the second year, the biochar did not show any effect. The best impact on nitrous oxide emissions was produced by the highest amount of biochar (10 tons per hectare). As it was noted in different studies, $\mathrm{N}_{2} \mathrm{O}$ emissions are likely to decrease with an increase in the amount of biochar used. This ratio was observed when the biochar additive constituted 40 tons per hectare [20].

Along with biochar properties, soil parameters must also be considered. It was shown that when acidic soils are treated with biochar, nitrous oxide emissions do not change. It was recommended to apply biochar to circumneutral soils [21]. Grain-size structure of soil also matters for biochar treatment, as, for example, in loamy soils, the decrease in nitrous oxide emissions is most manifested [22]. This can be explained by the fact that loamy soils have more capillary pores inside the aggregates than sandy or clay soils, and hence, they have better water hold capacity.

Some studies mention the correlation between soil temperature and nitrous oxide emissions regardless of the amount of biochar used. As the soil temperature drops, nitrous oxide emissions decrease $[6,19]$. Remarkably, in the field conditions, soil moisture does not affect the emission of gases [19].

However, the results obtained by scientists from different countries are far from being clear. Some studies showed an increase in nitrous oxide emissions due to the acceleration of the nitrification process [23]. To date, there is no well-elaborated system for applying biochar, which would take into account the properties of biochar, soil parameters, and the whole complex of exogenous factors. There is also lack of longitudinal studies that could estimate the long-term impact of biochar on soils.

Thus, there is a need for long-term multifactor field experiments that could add more insight to the problem of soil processes and contribute to the world knowledge base on the influence of biochar input on gas emissions.

It is for the first time that the effect of biochar applied to the soils of the Primorsky Region was examined and its influence on nitrous oxide emissions from agricultural soils (Endoargic Anthrosols) of the Primorsky Region was studied. These soils are characterized by a heavy particle size distribution and high density. In spring and summer, the soils are subject to moisture stagnation, which enhances greenhouse gas emissions. The problem is further aggravated by the intensive use of fertilizers, some of which evaporate into the atmosphere.

The aim of the study was to examine biochar effect on nitrous oxide emissions from Endoargic Anthrosols of the south of the Primorsky Region depending on the following factors: 1) different doses of biochar $\left(1 \mathrm{~kg}\right.$ per $\mathrm{m}^{2}$, or 10 tons per hectare, and $3 \mathrm{~kg}$ per $\mathrm{m}^{2}$, or 30 tons per hectare); 2) the use of organic and mineral fertilizers; 3 ) the presence or absence of a drainage melioration system.

\section{Materials and methods}

The field experiment was carried out on the territory of the Primorsky Vegetable Experimental Station - a branch of the Federal State Budget Scientific Institution "Federal Research Center for Vegetable Production" (43 ${ }^{\circ} 25^{\prime} 22.4$ "N $132^{\circ} 18^{\prime} 50.6$ " E, Surazhevka village, Primorsky Region, Russia). The soils of the Primorsky Region are formed under the influence of monsoon climate. Thus, in winter they suffer from deep freezing, in spring they are subject to late thawing and the drying out of surface horizons above frozen layers. In summer the soils suffer from prolonged waterlogging on account of monsoon rains under high temperatures, and from drying out in autumn. The average daily temperature at the site 
during the experimental period (July, August, September, and October 2018) was $19.53{ }^{\circ} \mathrm{C}$, and the average daily humidity was $78.6 \%$.

The soils are represented by dark humic soils on deluvial deposits of clay-slates, according to the Soil Field Guide [24], or Endoargic Anthrosols (Endoclayic), according to the World Reference Base for Soil Resources [25]. The soils are characterized by a heavy particle size distribution, low humus content and excessive waterlogging [26].

One of the experimental sites has a subsurface drainage system in the form of drainage pipes (drains) laid at a depth of $120 \mathrm{~cm}$ along the entire perimeter of the drained area.

The biochar used in the experiment (produced by "Krasilov \& Co" company) was made from wood residues of the Betula alba birch by pyrolysis at $360-380{ }^{\circ} \mathrm{C}$. It was applied in doses of $1 \mathrm{~kg} / \mathrm{m}^{2}$ and $3 \mathrm{~kg} / \mathrm{m}^{2}$ to topsoil $(0-29 \mathrm{~cm})$ in June 2018 .

The amount of carbon in biochar estimated $95.663 \%$, the ash content was $4.1-6.4 \%$ depending on the biochar fraction size, and volatile matters ranged from $23.5 \%$ to $26.9 \%$, with $\mathrm{pH}$ level being 8.09. Calcium, sodium, and magnesium rates were 17.7, 5.7 and 4.2 $\mathrm{mg} / \mathrm{kg}$ of the dry weight of biochar, respectively [27].

The first measurements of nitrous oxide emissions were taken one month after applying the biochar (July) and were then carried out every two weeks until the end of October 2018.

In Endoargic Anthrosols, the topsoil texture varies from clay loam to light clay. In terms of acidity, it is weak acid being close to neutral in the topsoil. By carbon content, the surface horizons are slightly humic. The main profile-forming process is illimerization (lessivage).

Nitrous oxide emissions from soil were examined with the G2508 gas analyzer (Picarro). For each experiment, four tests were conducted, and each test included three soil samples. The aluminum boxes with soils were placed in a closed one-liter glass chamber. Gas emissions were measured for 300 seconds (the data obtained made it possible to estimate nitrous oxide emissions from the soil). After that, the information was compared to temperature, pressure, and humidity in the laboratory and the field during the experiment.

Using the emission data, cumulative gas flows $\left(\mathrm{mg} \mathrm{N}_{2} \mathrm{O}-\mathrm{N} / \mathrm{m}^{2} *\right.$ hour$)$ were estimated together with a standard deviation $\left(\mathrm{R}^{2}\right)$, which made it possible to assess the validity of the results obtained.

\section{Results and discussion}

One month after applying biochar to the soil, positive results were obtained showing a decrease in nitrous oxide emissions. When biochar was added to the soil at a dose of 1 $\mathrm{kg} / \mathrm{m}^{2}$, nitrous oxide emissions decreased by $52.2 \%$, while $3 \mathrm{~kg} / \mathrm{m}^{2}$ biochar reduced the emissions by $97.8 \%$ compared to the referent. Biochar is supposed to be an inhibitor of denitrification, and this effect is displayed through an increase in porosity and aeration of the soil. The best effect was observed when applying biochar at a dose of $3 \mathrm{~kg} / \mathrm{m}^{2}$. The study confirmed the hypothesis (previously put forward by other scientists) that nitrous oxide emissions decrease as biochar doses grow.

The analysis of $\mathrm{N}_{2} \mathrm{O}$ cumulative flows in different periods of the experiment does not allow us to draw a definite conclusion about biochar dynamics (Figure 1). During the second month of biochar treatment, the emissions sharply fell and then continued to decline until the end of October. The emission reduction can be conditioned by nitrogen removal due to cabbage growing in the experimental field and requiring a lot of nutrients during its apical bud growth period [28]. The analysis of the cabbage biomass did not reveal excessive amounts of nitrates and nitrites. 


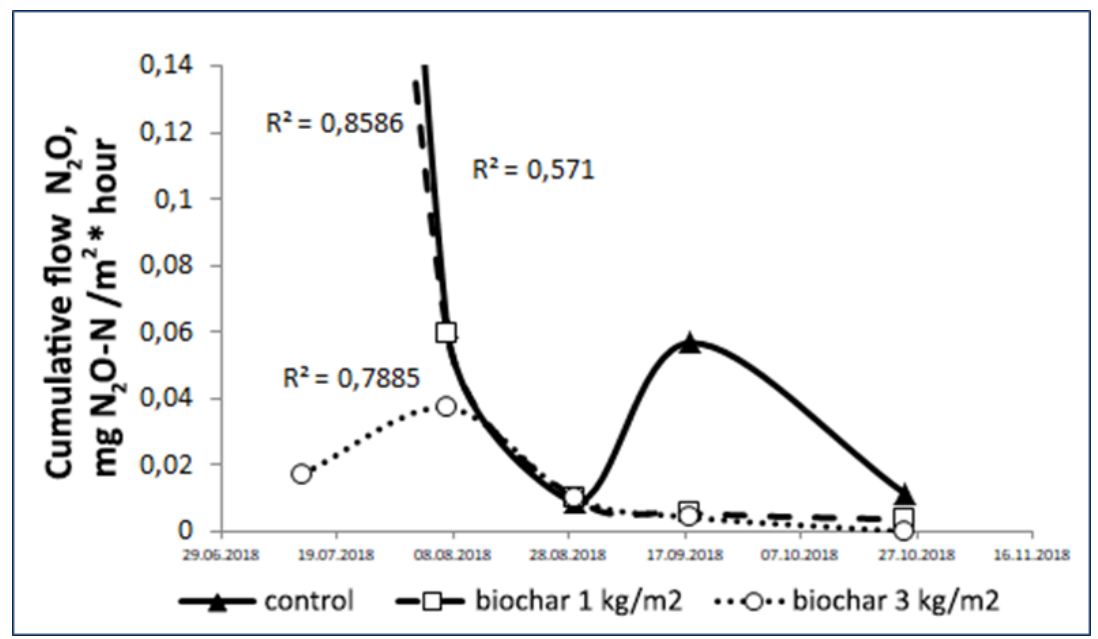

Fig. 1. The cumulative flow of $\mathrm{N} 2 \mathrm{O}$ from Endoargic Anthrosols, for four months of observations.

In early August, a decrease in the nitrous oxide emissions was observed, with biochar applied at doses of $1 \mathrm{~kg} / \mathrm{m}^{2}$ и $3 \mathrm{~kg} / \mathrm{m}^{2}$ - by $3.4 \%$ and $39.6 \%$, respectively. At the end of August, $\mathrm{N}_{2} \mathrm{O}$ emissions in the samples treated with biochar appeared to be greater than in the control samples (by 17.8\% and 15.4\%). In September, biochar reduced gas emissions by $90 \%$, regardless of its amount applied. In October, biochar at a dose of $3 \mathrm{~kg} / \mathrm{m}^{2}$ had a noticeable effect being able to reduce the cumulative nitrous oxide emissions by $99.4 \%$, while a lower dose of biochar could reduce the emission by only $68.1 \%$ compared to the control sample.

Overall, it seems possible to claim the cumulative effect of biochar, since the nitrous oxide emissions continued to decrease over time after applying biochar in any doses. Thus, after applying biochar at a dose of $1 \mathrm{~kg} / \mathrm{m}^{2}$, the initial nitrous oxide emission (that of July 13, 2018) decreased 142 times by the end of the experiment (October 25, 2018), and after applying biochar at a dose of $3 \mathrm{~kg} / \mathrm{m}^{2}$ the emissions dropped 238 times.

Considerable changes in gas emissions were not conditioned by biochar activity alone over time, but by seasonal changes in microbial activity, air circulation, precipitation, and other external factors, and these effects still need clarifying.

Despite the seemingly obvious problem of accelerating global warming, the production and use of fertilizers in agriculture continue to grow steadily, which consequently causes the increase in fertilizer emissions to the atmosphere and hydrosphere.

The study of the influence of mineral and organic fertilizers on the nitrous oxide emission and cumulative flow from Endoargic Anthrosols took 4 months. After a month of biochar treatment, there were no particular changes in nitrous oxide emissions observed. Nevertheless, a trend could be noted that while proceeding from a lower dose of biochar to a larger one, a decrease in emissions was observed.

During the first month of the experiment (July 13, 2018), there was a $17.5 \%$ decrease in nitrous oxide emissions, with mineral fertilizers and biochar used at a dose of $1 \mathrm{~kg} / \mathrm{m}^{2}$. The emissions dropped by $85.3 \%$ with biochar applied at a dose of $3 \mathrm{~kg} / \mathrm{m}^{2}$ compared to the control sample (Figure 2). A sharp increase in cumulative flows in the control sample in early August (August 7, 2018) could be explained by washing out nitrogen fertilizers due to rainfall and their further evaporation, whereas in other samples the biochar may have absorbed nitrogen fertilizers thus having prevented their evaporation. 


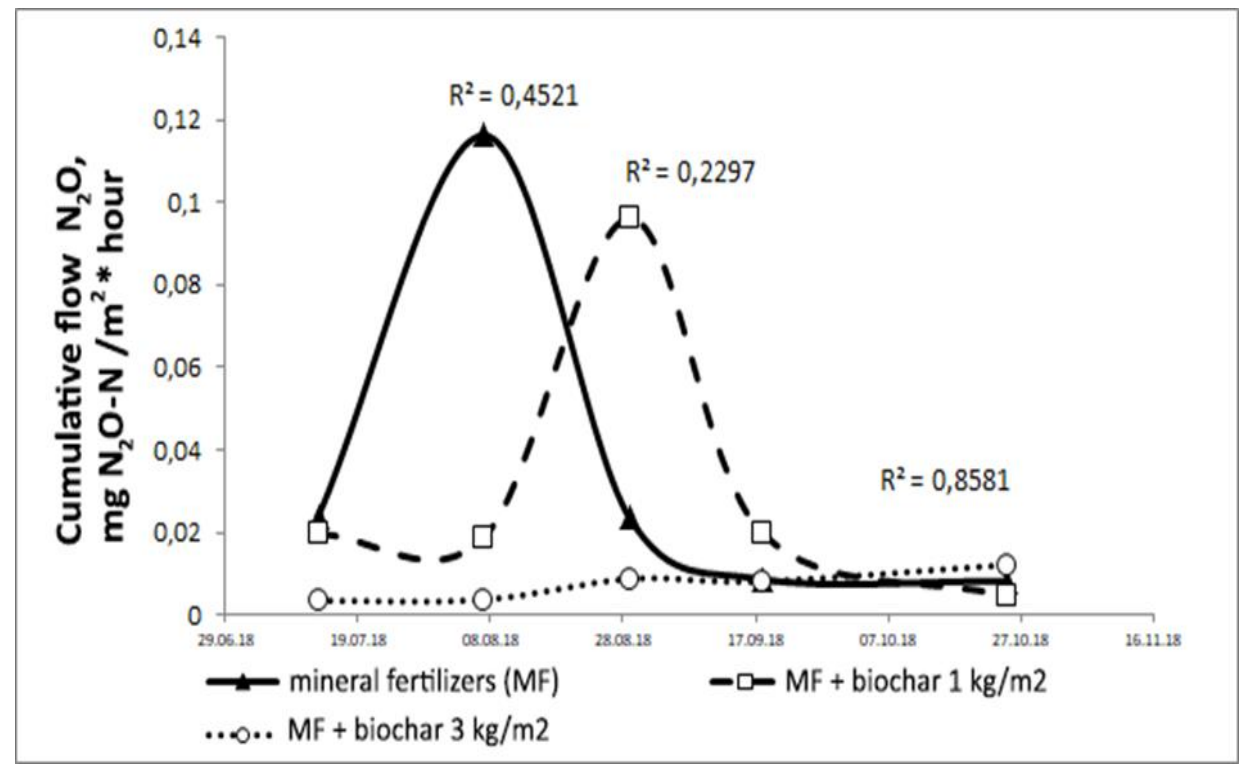

Fig. 2. The cumulative flow of $\mathrm{N} 2 \mathrm{O}$ from Endoargic Anthrosols with mineral fertilizers and biochar combined, for four months of observations.

In late August (August 29, 2018), there was a case of a larger emission from the soil where fertilizers and biochar were applied at a dose of $1 \mathrm{~kg} / \mathrm{m}^{2}$. Yet, in the following months of the experiment, it was rather difficult to identify a general tendency for nitrous emissions with mineral fertilizers applied. In September, the biochar flow at a dose of 1 $\mathrm{kg} / \mathrm{m}^{2}$ stood out of the total dataset again, while the flows from the control sample and the sample with biochar used at a dose of $3 \mathrm{~kg} / \mathrm{m}^{2}$ were approximately equivalent. Further on, in October, nitrous oxide emissions were higher in the sample with large amounts of mineral fertilizers and biochar than in other samples.

Summing up, one can see a positive initial effect of biochar on nitrous oxide emissions from the soil with mineral fertilizers. However, it was quite a short-term effect, and there was not any significant impact of biochar input on nitrous oxide emissions in the second part of the experiment.

Applying organic fertilizers has a positive effect on the soil by increasing albuminous nitrogen and microbial activity, which significantly increases the rate of nitrogen decomposition. The organic fertilizer used in the experiment was "Gigantin" made from chicken droppings $\left(1.25 \mathrm{~kg} / \mathrm{m}^{2}\right)$.

As the data showed, the nitrous oxide emissions in the sample with organic fertilizers are on average 5 times less than in the sample with mineral fertilizers, as the fertilizers are partially washed out of the soil by the surface and subsoil runoff (seepage). A month after the biochar and "Gigantin" were applied, there were no significant fluctuations in the values of nitrous oxide emissions from different soil samples, but a tendency to their increase in the control sample was noticed (Figure 3). 


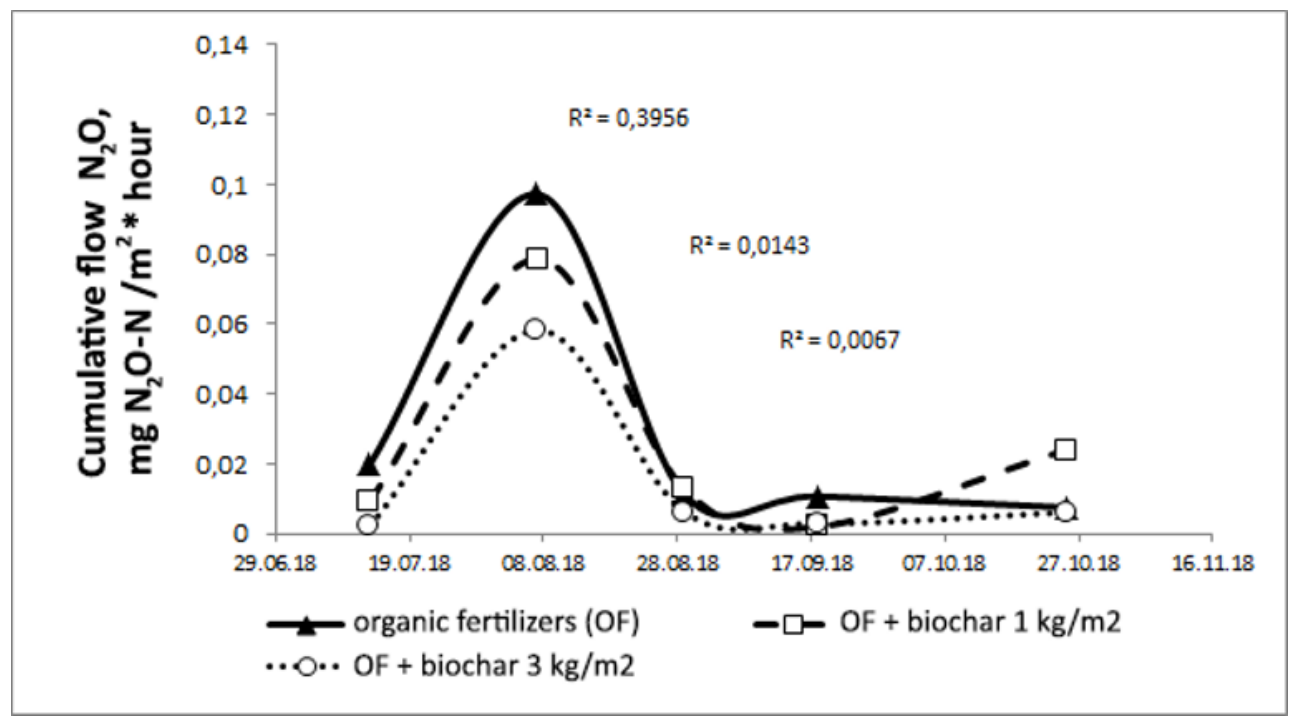

Fig. 3. The cumulative flow of $\mathrm{N} 2 \mathrm{O}$ from Endoargic Anthrosols with organic fertilizers and biochar combined, for four months of observations.

During the first month (July 13, 2018), a $1 \mathrm{~kg} / \mathrm{m}^{2}$ doze of biochar together with organic fertilizers reduced the flow by $53.7 \%$, and a $3 \mathrm{~kg} / \mathrm{m}^{2}$ doze of biochar lead to $88.9 \%$ reduction.

At the beginning of the second month, there was a sharp increase in all emissions, which can be explained by growing microbial activity. It can be caused by a rise in air and soil temperature under the influence of south-eastern tropical cyclones that prevail in the Primorsky Region in the second half of summer.

In early August (August 7, 2018) nitrous oxide emissions with biochar at a dose of 1 $\mathrm{kg} / \mathrm{m}^{2}$ appeared to be $19.1 \%$ less than in the control sample, and flows with biochar used at a dose of $3 \mathrm{~kg} / \mathrm{m}^{2}$ were $40.0 \%$ less. So, the biochar effect was less distinct during the second month of the experiment. In late August, September, and October, nitrous oxide emissions were declining. This can be explained by the removal of nitrogen by cabbage or by a gradual decrease in microbial activity during the coming cooling period.

In the second half of the experiment, the sample with biochar at a dose of $1 \mathrm{~kg} / \mathrm{m}^{2}$ showed mixed results: cumulative nitrous oxide emissions rise in late August, then fall in September, but grow again in October, whereas biochar used at a dose of $3 \mathrm{~kg} / \mathrm{m}^{2}$ continued to reduce nitrous oxide emission throughout the experiment.

Consequently, $3 \mathrm{~kg} / \mathrm{m}^{2}$ biochar proved to be the most effective in combination with both organic and mineral fertilizers, and it can be recommended for agricultural soils in the south of the Primorsky Region as a means of reducing nitrous oxide emissions.

During the field experiment, nitrous oxide emissions were seen in the samples with biochar added to the soils without a drainage system and the ones with drainage. A lighter particle texture and low moisture in the drained soil enable aerobic conditions and contribute to decreasing the denitrification process, the latter being responsible for nitrous oxide emissions to the atmosphere. Therefore, it was assumed that nitrous oxide emissions in the soil without drainage are higher than the ones in drained soils.

One month after applying biochar, the nitrous oxide emission in the control sample and the sample with $1 \mathrm{~kg} / \mathrm{m}^{2}$ biochar input in soils with drainage was significantly lower than in soils without drainage, while the emission from the soil with biochar at a dose of $3 \mathrm{~kg} / \mathrm{m}^{2}$ in the drained soil did not differ from the drain-free area. 
It is known that in soils with drainage, the utilization rate of fertilizer nitrogen increases by $30 \%$ [29]. Accordingly, the emission of nitrous oxide from the drained soil should be less than the emission from the soil without drainage. However, in the experiment, there was no significant difference between the samples with drained and drain-free soils.

In the control sample with organic fertilizers and the sample with organic fertilizers and biochar used at a dose of $3 \mathrm{~kg} / \mathrm{m}^{2}$, the nitrous oxide emission in the drain-free soils was slightly higher than in the soils with drainage, and in the sample with organic fertilizers and biochar at a dose of $1 \mathrm{~kg} / \mathrm{m}^{2}$, it remained approximately the same in both areas.

In early August (August 7, 2018), during the second month of the experiment, an increase in nitrous oxide emissions in the soils without drainage was observed, in comparison to the soil with drainage in all the samples.

At the end of August (August 29, 2018), the situation turned out to be the opposite - the emission in the sample without drainage was higher than in the sample with drainage, except for the sample with mineral fertilizers and biochar at a dose of $1 \mathrm{~kg} / \mathrm{m}^{2}$. In September and October, the results were mixed and varied greatly, so no definite trends could be revealed.

\section{Conclusion}

1. Biochar reduces the emission and cumulative flow of nitrous oxide in Endoargic Anthrosols of the south of the Primorsky Region. It was found that biochar used at a dose of $1 \mathrm{~kg} / \mathrm{m}^{2}$ reduced $\mathrm{N}_{2} \mathrm{O}$ cumulative flow from the soil by $52.2 \%$ and at a dose of $3 \mathrm{~kg} / \mathrm{m}^{2}$ by $97.8 \%$ for the entire period. During the experiment, $3 \mathrm{~kg} / \mathrm{m}^{2}$ biochar appeared to be more effective than a lower dose of $1 \mathrm{~kg} / \mathrm{m}^{2}$. The biochar effect on nitrous oxide emissions steadily decreased in all the tests over time.

2. Biochar used at a dose of $1 \mathrm{~kg} / \mathrm{m}^{2}$ in combination with organic fertilizers reduces nitrous oxide emissions by $53.7 \%$, and at a dose of $3 \mathrm{~kg} / \mathrm{m}^{2}$ - by $88.9 \%$. After 4 months, the nitrous oxide emission in the sample with biochar at a dose of $1 \mathrm{~kg} / \mathrm{m}^{2}$ was 3 times higher than in the control sample, and with biochar at a dose of $3 \mathrm{~kg} / \mathrm{m}^{2}$ the emission was 1.2 times lower. Biochar at a dose of $3 \mathrm{~kg} / \mathrm{m}^{2}$ turns out to be more effective when combined with organic fertilizers.

3. Biochar used at a dose of $1 \mathrm{~kg} / \mathrm{m}^{2}$ in combination with mineral fertilizers reduced the nitrous oxide flow by $17.5 \%$, and under $3 \mathrm{~kg} / \mathrm{m}^{2}$ biochar combined with mineral fertilizers, the emission decreased by $85.3 \%$. After 4 months, the nitrous oxide emission in the sample with mineral fertilizers and biochar at a dose of $1 \mathrm{~kg} / \mathrm{m}^{2}$ decreased by $44.6 \%$, while in the sample with biochar at a dose of $3 \mathrm{~kg} / \mathrm{m}^{2}$ it increased by $47.5 \%$. Biochar at a dose of 1 $\mathrm{kg} / \mathrm{m}^{2}$ appears to be more effective for reducing nitrous oxide emissions than biochar used in the amount of $3 \mathrm{~kg} / \mathrm{m}^{2}$.

4. The difference in nitrous oxide emissions in the soils with a drainage system and without it is significant only in the first two months after applying biochar. On the whole, neither drainage nor its absence influence biochar input, since it reduces nitrous oxide emissions in both experimental tests.

This study was funded by the Russian Foundation for Basic Research (project No. 19-29-05166).

\section{References}

1. R.Q. Grafton, C. Daugbjerg, M.E. Qureshi, Food Security 7(2), 179 - 183 (2015) doi: 10.107/s12571-015-0444-X

2. Rodriguez, I.R. Sanders, ISME Journal 9(5), 1053 - 1061 (2015) doi: 10.1038/ismej.2014.207 
3. V.N. Kudeyarov, Eurasian Soil Science, 52 (1), 94-104 (2019) doi: 10.1134/S0032180X1901009X

4. W.L. Gao, H. Yang, L. Kou, S.G. Li, Journal of Soils and Sediments, 15 (4), 863 879 (2015) doi: 10.1007/s11368-015-1087-5

5. Z.L. Cui, H.Y. Zhang, X.P. Chen, F.S. Zhang, Nature, 555, 363 - 366 (2018) doi: 10.1038/nature25785

6. J. Zhang, C. Peng, Q. Zhu, W. Xue, Y. Shen, Y.Z. Yang, G.H. Shi, S.W. Shi, M. Wang, Atmospheric Environment, 142, 340-350 (2016) doi: 10.1016/j.atmosenv.2016.08.011

7. Zhang, G. Cheng, Q. Hussain, M. Zhang, H. Feng, M. Dyck, Field Crops Research, 205, 45 - 54 (2017) doi: 10.1016/j.fcr.2017.02.00C

8. Environmental Protection Agency (EPA), 675 (2017)

9. K. Cameron, H. Di, J. Moir, Annals of Applied Biology, 162, 145 - 173 (2013) doi: 10.1111/aab.12014

10. S. Li, L. Song, Y. Jin, S. Liu, Q. Shen, J. Zou, AMB Express, 6 (37), 1-9 (2016) doi: 10.1186/s13568-016-0208-X

11. M.L. Gitarskii, R.T. Karaban', D.E. Konyushkov, I.M. Nazarov, A.A. Romanovskaya, Eurasian Soil Science, 33 (8), 822-827 (2000)

12. B. Zhou, F. Yanfang, W. Yueman, Y. Linzhang, X. Lihong, X. Baoshan, Chemosphere, 204, 474-482 (2018) doi: 10.1016/j.chemosphere.2018.04.056

13. C. Maucieri, Y. Zhang, M.D. McDaniel, M. Borin, M.A. Adams, Geoderma, 307, 267276 (2017) doi: 10.1016/j.geoderma.2017.07.028

14. F. Wu, Z. Jia, S. Wang, S.X. Chang, A. Startsev, Biology and Fertility of Soils, 49 (5), 555-565 (2013) doi: 10.1007/s00374-012-0745-7

15. N. Fiorentino, M.A. Sánchez-Monedero, J. Lehmann, A. Ender,s M. Fagnano, M.L. Cayuel, Soil Biology and Biochemistry, 131, $166-175$ (2019) doi:10.1016/j.soilbio.2019.01.005

16. S. Mandal, B. Sarkar, N. Bolan, J. Novak, Y.S. Ok, L. van Zwieten, B.P. Singh, M.B. Kirkham, G. Choppala, K. Spokas, R. Naidu, Critical Reviews in Environmental Science and Technology, 46 (17), 1367-1401 (2016) doi: 10.1080/10643389.2016.1239975

17. J. Lehmann, M. Rillig, J. Thies, C. Masiello, W. Hockaday, D. Crowley, Soil Biology and Biochemistry, 43, 1812-1836 (2011) doi: 10.1016/j.soilbio.2011.04.022

18. B. Liang, J. Lehmann, D. Solomon, S. Sohi, J.O. Skjemstad, F.J. Luiza, M.H. Engelhard, E.G. Neves, S. Wirick, Geochimica et Cosmochimica Acta, 72 (14), 6069 - 6078 (2008) doi: 10.1016/j.gca.2008.9.028

19. X. Lu, Y. Li, H. Wang, B.P. Singh, S. Hu, Y. Luo, J. Li, Y. Xiao, X. Cai, Y. Li, Agricultural and Forest Meteorology, 271, 168-179 (2019) doi: 10.1016/j.agrformet.2019.03.001

20. Q. Liu, Y. Zhang, B. Liu, J.E. Amonette, Z. Lin, G. Liu, Z. Xie, Plant and Soil, 426, 211 - 225 (2018) doi: 10.1007/s11104-018-3619-4

21. P. Brassard, S.H. Godbout, J. Palacios, T. Jeanne, R. Hogue, R. Dubé, I. Limousy, L. Raghavan, Geoderma, 327, 73-84 (2018) doi: 10.1016//j.geoderma.2018.04.022

22. E. Verhoeven, E. Pereira, C. Decock, E. Suddick, T. Angst, J. Six, Journal of Environmental Quality, 46 (2), 237-246 (2017) doi: 10.2134/jeq2016.10.0396 
23. M. Sánchez-García, A. Roig, M.A. Sánchez-Monedero, M.L. Cayuela, Frontiers in Environmental Science, 2 (25), 1-10 (2014) doi: 10.3389/fenvs.2014.00025

24. Soil Field Guide (Dokuchaev Soil Institute, Moscow, 2008)

25. World Reference Base for Soil Resources. International soil classification system for naming soils and creating legends for soil maps. World Soil Resources Reports no. 106. (FAO, Rome, 2014)

26. A.D. Popova, V.A. Semal, Proceedings of the 1st International Conference on North East Asia Biodiversity, 165 (2018)

27. M.A. Bovsun, Y.A. Kolesnikova, A.D. Popova, O.V. Nesterova, V.A: Semal, Proc. 22nd Int. Forum Nature without Borders, 2018, Vladivostok, 2018 http://www.biosoil.ru/Files/00015969.pdf

28. G.I. Tarakanov, V.D. Muhin, K.A. Shuin, N.V. Borisov, V.V. Klimov, Vegetable Growing: A Study Guide (KolosS, Moscow, 2003)

29. Y.I. Mitrofanov, O.N. Antsiferova, L.V. Pugachyova, O.V. Karaseva, T.N. Panteleeva, Agriculture, 6, 24-27 (2016) 